Western University

Scholarship@Western

Department of Economics Research Reports

Economics Working Papers Archive

1971

\title{
On the Equivalence of Community Indifference and the Aggregate Consumption Function
}

James R. Melvin

Follow this and additional works at: https://ir.lib.uwo.ca/economicsresrpt

Part of the Economics Commons

Citation of this paper:

Melvin, James R.. "On the Equivalence of Community Indifference and the Aggregate Consumption Function." Department of Economics Research Reports, 7104. London, ON: Department of Economics, University of Western Ontario (1971). 
RESEARCH REPORT 7104

ON THE EQUIVALENCE OF COMMUNITY INDIFFERENCE AND THE AGGREGATE

CONSUMPTION FUNCTION

by

James R. Melvin

Departinent of Ecoscuits Lheray

NOV 21983

Hiversity of Western Ontario

Enson in - 
ON THE EQUIVALENCE OF COMMUNITY INDIFFERENCE

AND THE AGGREGATE CONSUMPTION FUNCTION

James R. Melvin Department of Economics University of Western Ontario

London, Ontario, Canada

February, 1971 


\section{On the Equivalence of Community Indifference and the Aggregate Consumption Function*}

\section{Introduction}

There exist in the economic literature two quite different types of macro economic models. One is the Keynesian model concerned primarily with internal equilibrium and in which unemployed resources are almost invariably assumed to exist, and the other is the classical model employed in trade theory, which is primarily concerned with external equilibrium, and which invariably assumes full employment. As both are aggregate models, in both, lurking in the background, we have the question of the conditions under which the various central parameters of the two can be aggregated. There are, of course, variables which are common to both models. In both we have the question of conditions under which aggregate commodities can be defined (one commodity in the Keynesian model and two in the international trade mode1), and closely related to this, the questions of when we can aggregate labor and capital. ${ }^{1}$ With respect to the aggregation question the main area in which the two models differ is the treatment of the demand side, for while in the Keynesian model it is the question of whether individual consumption functions can be aggregated that is important, in the trade model the important question is when aggregate utility functions can be defined. While the first of these questions does not receive a disappropriate amount of attention in

* I am indebted to the Canada Council for a research grant which supported the research for this paper, and I would like to thank Russ Boyer for valuable comments on an earlier draft.

${ }^{1}$ Actually, since in the Keynesian model there is a single output, the ability to aggregate this output implies that capital, and therefore investment can also be aggregated. 
the theoretical discussions of Keynesian models, the latter problem always seems to cast a shadow on international trade discussions, and indeed the severe conditions under which this aggregation is possible is often regarded as a major difficulty associated with the traditional diagrammatic techniques of international trade theory. Trade theorists themselves are very sensitive to these difficulties and constantly apologize for using community indifference curves. The purpose of this paper is to present a simple demonstration that the two aggregation problems referred to above are equivalent. That is, we will show that from a theoretical point of view, the conditions which are necessary and sufficient for the derivation of an aggregate consumption function are equivalent to the conditions which are necessary and sufficient for the existence of a set of community indifference curves. Thus the existence of a community indifference curve is a necessary and sufficient condition for the existence of an aggregate consumption function.

It should be made clear at the beginning, however, that we are not suggesting that an aggregate consumption function is not a meaningful concept even if all the conditions for its existence from a theoretical point of view are not met. From an empirical point of view the departures from these conditions will be important only if the bias associated with such departures is significant, and that is not a topic which will concern us here. ${ }^{2}$ Our only purpose is to show the equivalence of these two aggregation problems from a theoretical point of view.

2 For a review of the relevant literature and a discussion of this question see H. A. John Green, Aggregation in Economic Analysis (Princeton: Princeton University Press, 1964) Chapter 12. 
II. The Aggregate Consumption Function

We first consider the question of the conditions under which individual consumption functions can be aggregated. ${ }^{3}$ In general terms, consider the set of $\mathrm{n}$ functions

$$
y_{j}=f_{j}\left(x_{1 j} \cdots x_{i j} \cdots x_{m j}\right), \quad(j=1, \ldots n) .
$$

It is assumed that $x_{i j} \geqq 0$ and that the $f_{j}$ are continuous and differentiable. We want to determine the conditions under which these $\mathrm{n}$ functions can be aggregated to yield

$$
y=F\left(x_{1}, \ldots x_{m}\right)
$$

where

$$
y=y\left(y_{1}, \ldots y_{j}, \ldots y_{n}\right)
$$

$$
x_{i}=x\left(x_{i 1}, \ldots x_{i j} \ldots x_{i n}\right), \quad(i=1, \ldots m) .
$$

Green $^{4}$ has shown that if

$$
y=\sum_{j=1}^{n} y_{j} \quad ; \quad x_{i}=\sum_{j=1}^{n} x_{i j} \quad(i=1, \ldots m),
$$

then a necessary and sufficient condition for consistent aggregation is that the $f_{j}$ must be linear with identical slopes. ${ }^{5}$ That is, they must be of the form

(5) $y_{j}=a_{j}+\sum_{i=1}^{m} b_{i} x_{i j}$.

${ }^{3}$ Our approach here closely follows that of Green, ibid., Chapter 5 .

4 Ibid., pp. 39-40.

${ }^{5}$ Green, ibid., p. 35, defines consistency to mean that "... a knowledge of the 'macro-relation' (the function relating the aggregates), and of the values of the aggregate independent variables, would lead to the same value of the aggregate dependent variable as a knowledge of the micro-relations and of the values of the individual independent variables." 
In terms of consumption functions written as functions of income only, this result means that the consumption function for individuals can be aggregated to yield an aggregate consumption function if and only if (a) the consumption functions for all individuals are linear, and (b) all individuals have the same marginal propensities to consume. ${ }^{6}$ Thus we would have

$$
c_{j}=a_{j}+b_{j},
$$

where $c_{j}$ and $y_{j}$ are, respectively, the consumption and income of individual $j$. This does not mean, of course, that there are no other circumstances under which aggregation is possible, for if the independent variables can be constrained then aggregation may be possible under less severe circumstances. Thus, for example, if all incomes are constrained to move proportionately, then individuals need not have the same marginal propensities to consume, although all the functions must still be linear. ${ }^{7}$ Our concern in this paper is with the unconstrained case.

\section{The Community Utility Function}

We now consider equations ( 1 ) to be the utility functions for $n$ individuals and seek conditions for the consistent aggregation of these functions to yield equation (2). In this case, however, it is appropriate (and necessary) to impose a constraint; namely the condition that perfect competition prevails so that the marginal rate of substitution between any

${ }^{6}$ For other discussions of this question see H. Theil, Linear Aggregation of Economic Relations (Amsterdam: North Holland Publishing Co., 1954) Chapter 2, and John S. Chipman, "A Survey of the Theory of International Trade: Part 2, The Neo-Classical Theory," Econometrica, 33 (October 1965) p. 693.

${ }^{7}$ For a discussion of this case see Green, op. cit., p. 61, Theil loc.cit., and Chipman, loc.cit. It is not clear, however, that this method of aggregation is of much interest in Keynesian models. In macro models where unemployment exists, and where the discussion centers around reducing this unemployment, it would seem particularly unreasonable to assume that the incomes of all individuals must move proportionately. 
pair of goods will be the same for all individuals and equal to the ratio of their prices. Then assuming that all indifference surfaces are smooth and convex to the origin, and assuming again that

$$
x_{i}=\sum_{j=1}^{n} x_{i j}, \quad(i=1, \ldots m)
$$

it can be shown that a necessary and sufficient condition for the consistent aggregation of the $f_{j}$ to $F$ is that all income-consumption curves are linear, and that they have the same slope for all individuals. Furthermore, if the $f_{j}$ are defined for all non-negative values of the $x_{1 j} \cdots x_{m j}$, and if the marginal conditions of utility maximization hold for all values of the $x_{1}, \ldots x_{j m}$, then all the income consumption curves will pass through their respective origins. 8

As in the case of the aggregation of consumption functions, this does not mean that there are no other circumstances under which aggregation is possible, for if one is willing to impose additional constraints, aggregation may be possible. Chipman, for example, has shown that if the endowments of all individuals are proportional to the aggregate, then aggregation is possible even if the utility functions for all individuals are not the same, that is, even if the income-consumption curves do not have the same slope for all individuals. ${ }^{9}$ All income-consumption curves must, however, be linear. This situation is analogous to the case where consumption functions can be aggregated if all incomes are proportional.

${ }^{8}$ See Green, op. cit., pp. 47-50. We will hereafter constrain the incomeconsumption curves to go through the origin, in which case Green, ibid., has shown that $\mathrm{F}$ will be homogeneous of degree one.

${ }^{9}$ Chipman, op. cit. pp. 690-5. This situation is a curious one, however, for when the utility function can be defined only by constraining endowments, we no longer have the usual dichotomy between preferences and the budget constraint. 


\section{The Proof of Equivalence}

In the Keynesian model the individual consumer is seen to allocate his income between present consumption and future consumption, or, in other words, between present consumption and savings. He is thus viewed as having a utility function whose arguments are consumption and savings, which he attempts to maximize subject to his personal disposable income and given prices. Such a situation is shown in Figure 1, where the budget constraint $A B$ is determined by the individual's income and by the price level and the interest rate, and where utility is maximized at point $\mathrm{C}_{0}$. According to the arguments of Section II, in order that the consumption function for this individual satisfy the conditions for aggregation, it must be the case that increases in income result in linear increases in consumption. And to simplify matters we will assume that we are concerned with a long run consumption function such that if income is zero consumption is zero, that is, $a_{j}=0$ in equation (5). ${ }^{10}$ Thus, reducing income to one half of its former level so that $A^{\prime} B^{\prime}$ is the new budget line will halve consumption, and the new equilibrium point will be $\mathrm{C}^{\prime}$. The same argument holds for any change in income, and it is clear that this implies that all equilibrium points lie on the line $\mathrm{OC}_{0}$ extended. In other words, the conditions required to satisfy equation (5), i.e., the necessary and sufficient condition for the aggregation of the individual consumption functions, imply that the income consumption curve is a straight line through the origin. But this, from Section III, is

${ }^{10}$ This is by no means necessary, and a non-zero a could be retained as

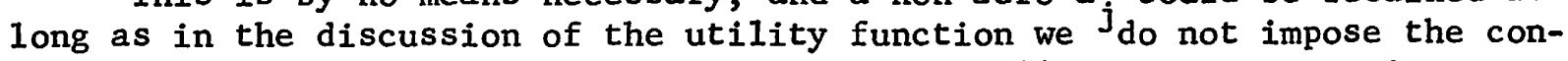
dition described in Section III that constrains all income consumption curves to go through the origin. For a discussion of the case where the income-consumption curves are not constrained to go through the origin see Green, ibid. Pp. 49-52, and W. M. Gorman, "Community Preference Fields," Econometrica, 21 (January 1953). 
$-7-$

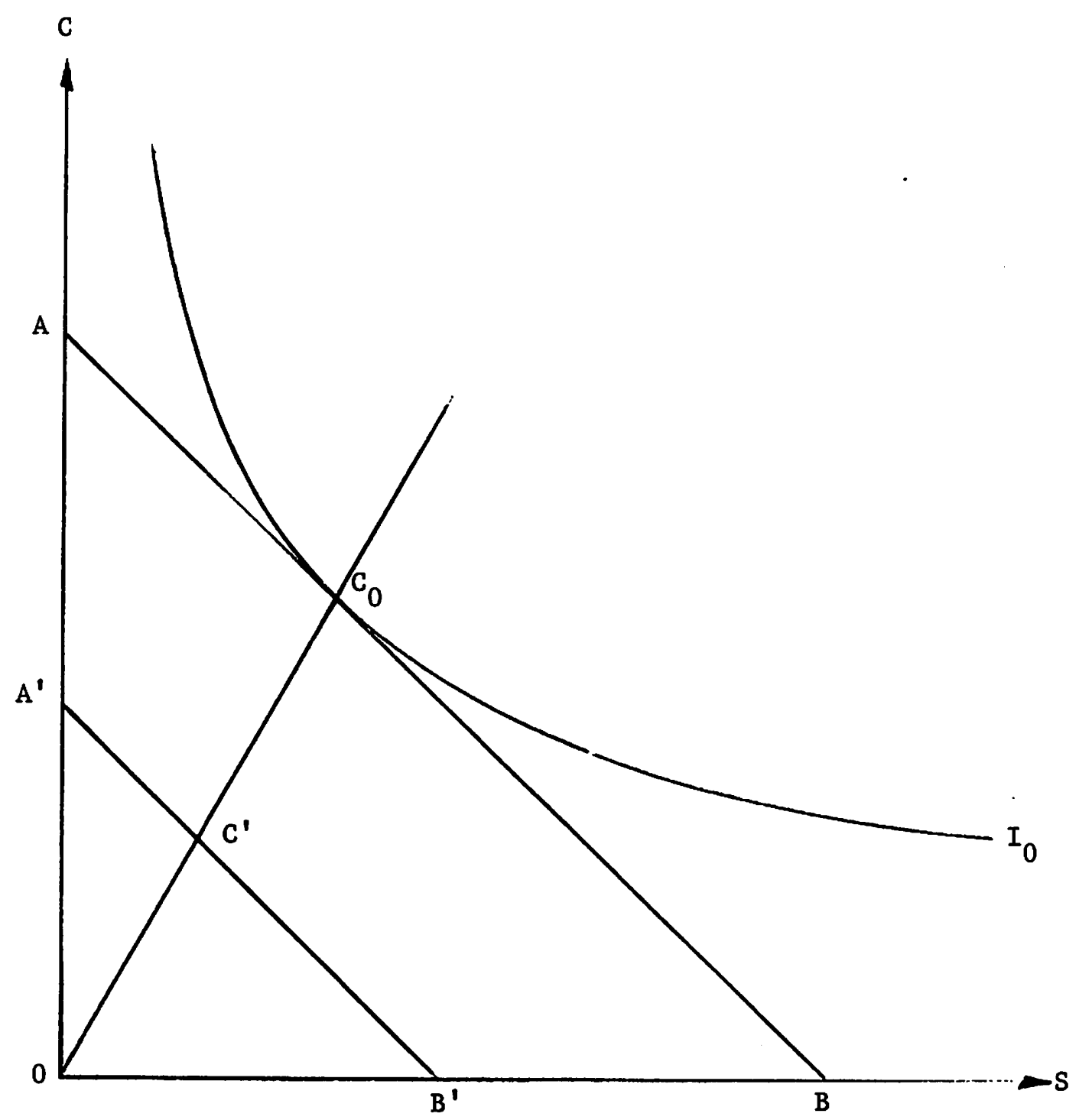

Figure 1 
the necessary and sufficient condition for the existence of a community utility function. It is therefore clear that, under the conditions which we have imposed, the existence of a community utility function is a necessary and sufficient condition for the existence of an aggregate consumption function.

\section{Summary and Conclusions}

The main purpose of this paper has been to demonstrate the equivalence between the concepts of community indifference and aggregate consumption. It may also be worthwhile observing that whereas the Keynesian economist would have a considerable amount of difficulty getting along without a consumption function, the international trade economist can, with few exceptions, get along quite nicely without community indifference curves. ${ }^{11}$ This has been demonstrated by Johnson and Kenen, ${ }^{12}$ who have shown that the offer curve, the standard international trade tool, can be derived even if individuals have different tastes. The underlying reason for this is that while in the Keynesian model output is a variable even with given prices, in the international trade model it is not, and this provides an additional degree of freedom in the classical model.

One other observation is perhaps in order. In a Keynesian model the utility function is an intertemporal one relating present and future consumption, while in the traditional trade model the utility function concerns two

11

One area in which community indifference curves would seem to be necessary is in the optimum tariff literature.

12 Harry G. Johnson, "International Trade, Income Distribution, and the offer Curve," Manchester School of Economic and Social Studies, 27 (September 1959), 241-60, and Peter B. Kenen, "Distribution, Demand and Equilibrium in International Trade: A Diagrammatic Analysis," Kyklos, 12 (fasc. 4, 1959). 
(or more) goods at a particular point in time. We have not meant to suggest that the likelihood of observing the necessary and sufficient conditions for the existence of the aggregate utility functions are the same in these two models, although a priori there seems to be no reason for believing one to be more likely than the other. Our argument has been only that the constraints that one must impose are the same in both cases, and we have made no judgement on the likelihood of these constraints being fulfilled in practice.

It may not be necessary to point out, in conclusion, that the purpose of this paper is not to question the validity of Keynesian aggregate economics. Rather our purpose is to persuade economists that as a theoretical construct, no more scorn should be attached to community indifference curves than is afforded the concept of aggregate consumption. 